\title{
The Research Doesn't Always Apply: Practical Solutions to Evidence-Based Training-Load Monitoring in Elite Team Sports
}

\author{
Darren J. Burgess
}

\begin{abstract}
Research describing load-monitoring techniques for team sport is plentiful. Much of this research is conducted retrospectively and typically involves recreational or semielite teams. Load-monitoring research conducted on professional team sports is largely observational. Challenges exist for the practitioner in implementing peer-reviewed research into the applied setting. These challenges include match scheduling, player adherence, manager/coach buy-in, sport traditions, and staff availability. External-load monitoring often attracts questions surrounding technology reliability and validity, while internal-load monitoring makes some assumptions about player adherence, as well as having some uncertainty around the impact these measures have on player performance This commentary outlines examples of load-monitoring research, discusses the issues associated with the application of this research in an elite team-sport setting, and suggests practical adjustments to the existing research where necessary.
\end{abstract}

Keywords: monitoring, player readiness, tracking technology, field sports

The prevention of excessive fatigue and injury and training prescription to improve performance remain critical goals of sport-science and sports-medicine practitioners (SSMPs) working in elite team sports. Unlike individual sports, SSMPs may have up to 90 players (eg, NFL preseason) to monitor, compelling effective practitioners to employ strategies to assess how similar training loads might affect each player individually. ${ }^{1}$ Furthermore, the ability to quantify training loads may augment periodization programs ${ }^{2}$ and reduce negative training adaptations. ${ }^{3}$ Typically in elite team sports, a suite of load-monitoring strategies is employed by SSMPs. This may consist of a combination of external (estimation of athletes work performed) and internal (estimation of physiological impact of this work) monitoring strategies.

Significant challenges exist for SSMPs in implementing monitoring strategies within an elite team sport environment. For instance, despite the strong evidence linking effective monitoring to enhancing numerous aspects of team performance, head coaches/managers often perceive these strategies with skepticism. In addition, player compliance can often be sporadic. Further, some sports such as association football (soccer), baseball, and basketball play multiple games in any given week across many locations. Here, SSMPs may prioritize activities of recovery and team travel over monitoring strategies as they may have a bigger impact on repeat performances. Finally, some monitoring strategies require expert staffing and additional technology expenditure, which is not always possible or practical in elite team sports.

The purpose of this commentary is to outline some common evidence-based load-monitoring strategies and describe their application in elite team-sport environments.

The author is with the School of Health Sciences, University of South Australia, Adelaide, Australia. Address author correspondence to dburgess@pafc.com.au.

\section{Monitoring External Load}

External load refers to the work performed by the athlete. ${ }^{4}$ Typically this involves quantifying movement demands and in team sports, is most commonly assessed using global positioning systems (GPS). Despite questions over the reliability of GPS, ${ }^{5}$ as well as inconsistencies in reported speed-zone classifications, ${ }^{6}$ metrics such as high-speed running, meters per minute, and player load have been researched and implemented in a variety of team sports. High-speed running volume in particular has been linked to performance in Australian Rules football (ARF), ${ }^{7}$ injury risk in rugby league $(\mathrm{RL})^{8}$ and the metabolic cost of training in soccer. ${ }^{9}$

The use of GPS technologies in elite team sports has increased markedly in the last decade. GPS units have become smaller and therefore more "player friendly"; consequently their use and importance in training load monitoring have increased. Despite these trends the periodization training model in team sports is often determined by the manager or coach. In this scenario the SSMPs can use GPS monitoring to identify any inappropriate training load progressions and attempt to educate coaches on more suitable alternatives. Practitioners are urged to use a "less is more" approach when reporting GPS metrics to previously uneducated (from a GPS point) coaches and players, as overloading players and coaches with technical information may lead to a lack of confidence in both the technology and staff.

When reporting GPS loads the typical variation in physical performance is often unaccounted for. ${ }^{10}$ This can create inappropriate commentary on performance from coaches/players. A solution to this issue is presented as Figure 1. This figure presents high-speed running (above $5.5 \mathrm{~m} / \mathrm{s}$ ) in matches. The lines above and below the estimated (dotted) line of best fit depict the typical error (SD) in this metric for this player. Expressing the data in this way makes it easier for the player and coach to understand actual performance fluctuations, as well as assess trends across a season.

One area in which SSMPs can determine the periodization of training is the rehabilitation setting. The rehabilitation program is commonly progressed outside of team training and therefore 


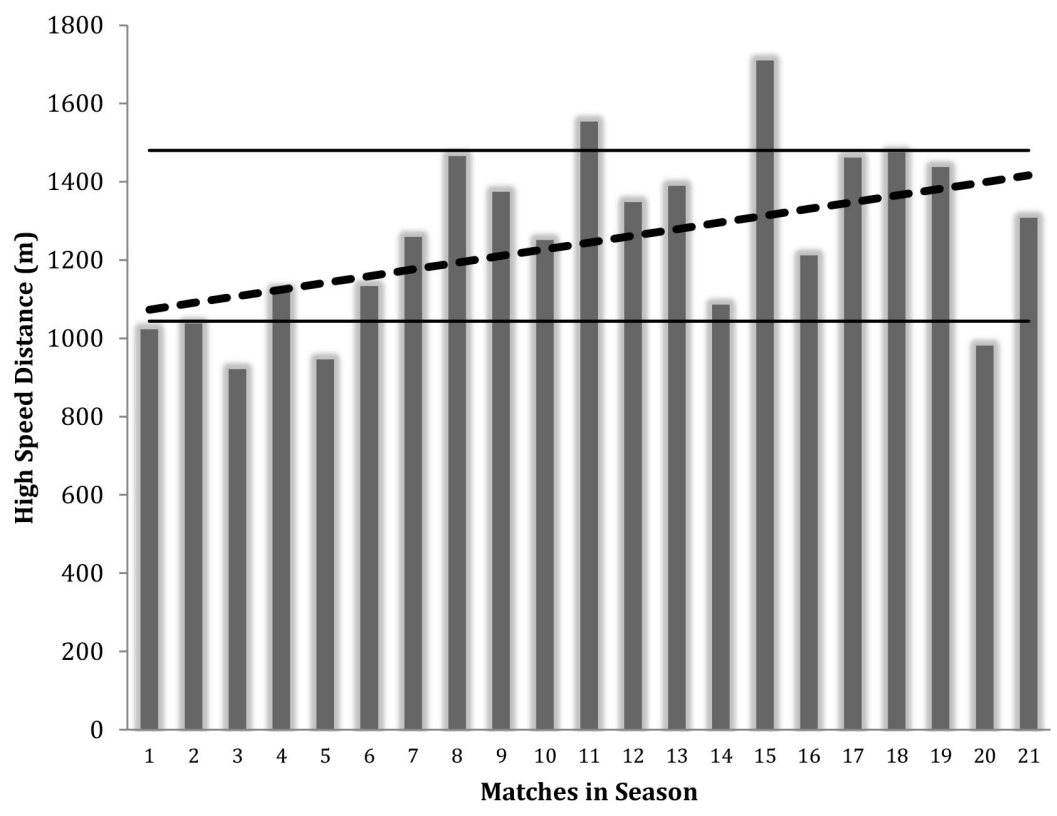

Figure 1 - High-speed-running distance across a season. A dashed line of best fit is placed indicating that the player has improved output across the season. Lines above and below represent typical error $(\mathrm{SD})$ of score for this player.

potentially without head coach/manager influence. The SSMPs can provide incremental increases in all relevant GPS metrics until the injured player has reached predetermined targets. ${ }^{11}$ An illustration of this process is found in Figure 2. This figure depicts the peak speed scores in a rehabilitation progression for a hamstring injury. The player had a peak speed of $9 \mathrm{~m} / \mathrm{s}$ (as measured by their maximum GPS score collected across their duration with the club) and was subjected to $10 \%$ increases per week beginning at $60 \%$ and reaching his peak speed the week before returning to play (RTP). The challenge for the SSMP is to align all relevant variables within the RTP time frame established while being cognizant of stabilizing acute:chronic training loads before RTP. ${ }^{12}$

Once familiarity has been established with GPS-based externalload monitoring, SSMPs can become more prescriptive with their monitoring. Recent applied research has established indicative guidelines for team-sport modeling of future training loads to help prevent injury and improve player readiness to perform..$^{8,13-15}$ SSMPs should however to establish their own guidelines for their players rather than rely completely on models established on different sporting populations.

Emerging technologies (accelerometers, inertial measurement units, etc) provide player load information without the need for access to satellites. Implementation into team sports environment should only occur once SSMPs have full understanding of what the technology output represents to fully educate players and coaches before their embedding into monitoring programs.

\section{Monitoring Internal Load}

Internal load is the relative physiological and/or psychological effect of the work performed ${ }^{16}$. In most elite team sports environments, internal load is commonly expressed as any 1 or a combination of session rating of perceived exertion (sRPE), subjective wellness estimates, and various heart-rate/blood-derived metrics.

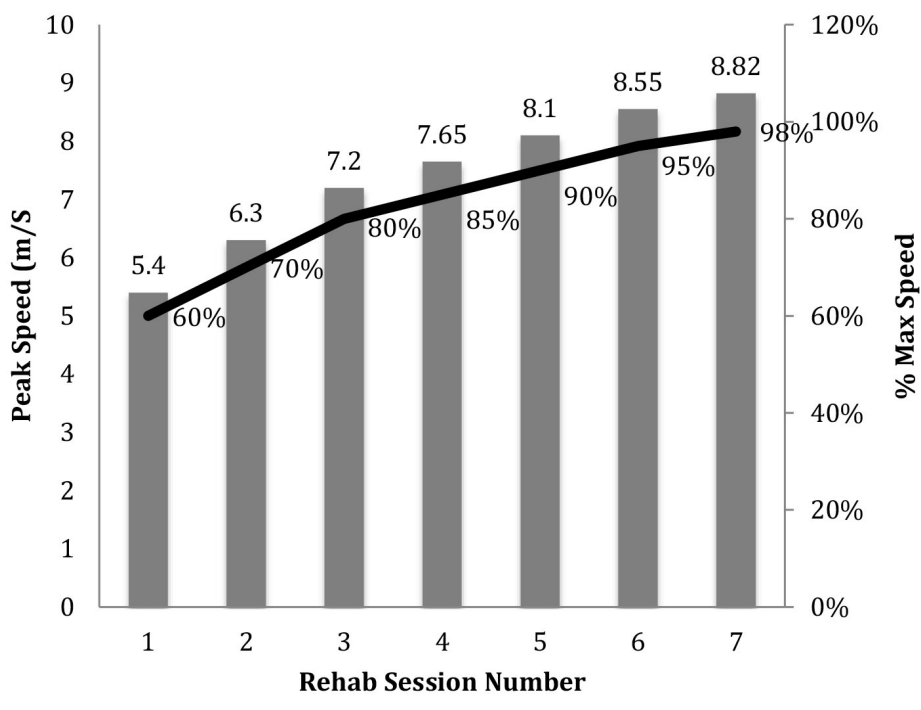

Figure 2 - Peak speed progressions in a rehabilitation setting. The bars represent peak speed and the line represents percentage of the player's maximum speed.

Despite limited published studies examining concurrent validity of sRPE in team-sport environments, ${ }^{17} \mathrm{sRPE}$ is the most commonly observed internal training load measure in team-sport research and practice. This is predominantly due to its ease of collection, negligible expense, and ability to quantify loads in all forms of training (conditioning, strength, rehabilitation, "off-legs," etc) and competition. ${ }^{18}$ sRPE has been correlated with injury incidence in rugby league, ${ }^{19}$ and ARF, ${ }^{15}$ and has also been successfully used to develop injury-prediction models for collision sports. ${ }^{20}$

The limitations in using sRPE in team sports include the number of scales available, ${ }^{17,21,22}$ the variability associated with the multiple 
factors involved in estimating $\mathrm{SRPE}^{23}$ and the conflicting reliability reported..$^{22}$ Practically, sRPE can be influenced by player education, language barriers, and method/timing of collection. Practitioners should ensure players fully understand how and when sRPE will be used to gain player trust in this measure. Measures should be taken in the same manner, at the same time shortly after each session, in the players' native language and, ideally, by the same SSMP.

Internal load may also be estimated using wellness questionnaires. These have been developed to assess perceived fatigue and wellness in team sports ${ }^{24}$ and share similar strengths (cost, ease of collection, etc) and limitations (player "buy-in," varying models, etc) as sRPE. While some questionnaires such as the RESTQ-Sport and POMS have been validated in team sports, ${ }^{25,26}$ the more common approach in the field has been for SSMPs to develop their own questionnaires relevant to their populations/situation. ${ }^{24,27}$ Initial validity concerns arising from these "adapted" questionnaires have been allayed with numerous studies demonstrating sensitivity to training-load changes. ${ }^{24,27,28}$

SSMPs are advised to establish their own validity of whichever questionnaire they choose. This becomes particularly important either when using an established questionnaire on a different population to that on which it was validated or when introducing an adapted questionnaire. The efficacy of any questionnaire can be improved in an applied setting by limiting exposure to 1 or 2 times per week, ensuring that the questionnaire is easy to understand, providing the questionnaire using available technology (eg, smartphone), ensuring follow-up dialogue with players when alerts are triggered and providing updates to players and coaches on how the results have influenced practice.

To support these aforementioned subjective measures there remains a need to provide more objective markers of internal load in elite team sports. Various blood and saliva assay markers (creatine kinase, testosterone, C-reactive protein, cortisol, etc) have been used to examine internal load through estimations of fatigue, immunological status, and even direct responses to training and match stimuli. ${ }^{29-34}$ Measures such as testosterone and creatine kinase have been shown to have relationships with performance in both $\mathrm{RL}^{35}$ and ARF. ${ }^{36}$ However in American football players variations of external load failed to produce any significant changes in metabolic markers of fatigue. ${ }^{37}$ In addition, monitoring of testosterone and cortisol levels across an entire ARF season failed to produce any meaningful relationships. ${ }^{38}$

The discrepancy in research findings in these with both blood and saliva markers in elite team sports is perhaps due to the high individual variability. ${ }^{39}$ For example, CK has demonstrated diurnal variation, as well as large individual variability depending on player position, ethnicity, and day of measurement (number of days pregame or post game). ${ }^{36}$ Typically the expense, time taken to measure and analyze, as well as player understanding of relationship to performance have resulted in restricted use of these measures.

Heart rate (HR) monitoring offers an objective, relatively inexpensive, and convenient insight into player internal load, particularly in a team-sport setting. ${ }^{40}$ In this environment team HR scores can provide the SSMPs with a snapshot of the team's physiological response to any training stimulus, providing an almost instant fitness assessment of the playing group. Knowledge of player maximum HR values allows practitioners to express HR scores relatively, providing even greater individualization in reporting and subsequent training.

Recently, heart-rate variability (HRV) has become a popular estimate of player fatigue state. ${ }^{41}$ Despite the popularity and convenience of HRV technology, caution should be applied as these values are extremely sensitive to diurnal factors, as well as activity and food and liquid consumption before measurement. ${ }^{42}$

Monitoring player sleep patterns has demonstrated some relationship with training-load fluctuations and injury occurrence. ${ }^{43}$ While emerging ActiGraphy technology has made the estimation of sleep quality and quantity more readily available, concerns still exist about the relationship between these technologies and goldstandard estimates of sleep using polysomnography. ${ }^{44,45}$ In addition, once a poor sleep pattern has been identified, interventions are necessarily retrospective and typically limited to education on proper sleep hygiene.

\section{Screening}

Regular screening of players has been used in team-sport settings to assess training adaptations, readiness to train, fatigue, impact of match, and injury-risk profile. There is considerable support for specific protocols in addition to those outlined previously in this paper such as hamstring strength, ${ }^{46}$ countermovement jump, ${ }^{47}$ various range-of-motion assessments, and movement-based protocols. ${ }^{48}$ However, debate remains as to whether these protocols actually assess readiness or injury risk. ${ }^{49}$ In addition, these assessments take considerable time, resources, and, in some cases, skill to implement. In elite team-sport environments, with up to 50 players in a squad, this can be quite cumbersome for both players and staff.

SSMPs need to be aware of these limitations and ensure that all assessments are executed in a reliable, valid manner. Validation should be specific to the population assessed, and where no validation exists in the literature SSMPs should perform in-house validation of any tool to be implemented. Staff are advised to select the minimum number of validated assessments required to achieve the goals of injury risk and readiness to train/play assessment.

\section{Combining Internal and External Load Monitoring}

In an applied environment with multiple players the ability for SSMPs to combine validated measures of internal and external load arguably offers the ideal monitoring scenario. Accurate assessments of work performed and cost of this work provides a constant fitness assessment of both individuals and teams. Evidence exists describing various internal/external load relationships in team sports. ., 17,25,26 $^{2}$ This research should inform SSMPs' decision making but rarely dictate it. Coaching and playing environment, as well as resources and available staff, should determine the tools to be implemented in any team-sport environment.

Where GPS (external load) and heart rate (internal load) are available, establishing the relationship between these measures may offer a snapshot of individual and team fitness. Figure 3 demonstrates this relationship in a single session. This figure depicts average HR and high-speed-running values with the "cross-hair" lines in the center representing group averages for the session. Players $1,2,3$, and 4 demonstrate appropriate work rate:cost ratios. Player 5 displays low work rate with a high cost and therefore warrants further investigation. Player 6 demonstrates high work rate with a low cost and therefore demonstrated superior fitness in this session.

The emerging research on heart-rate recovery (HRR) as an indicator of player fitness/readiness also combines internal and external load. SSMPs could use this concept in 2 scenarios. First, HRR can be assessed within training sessions where a set period of work could be performed followed by an appropriate, standardized 


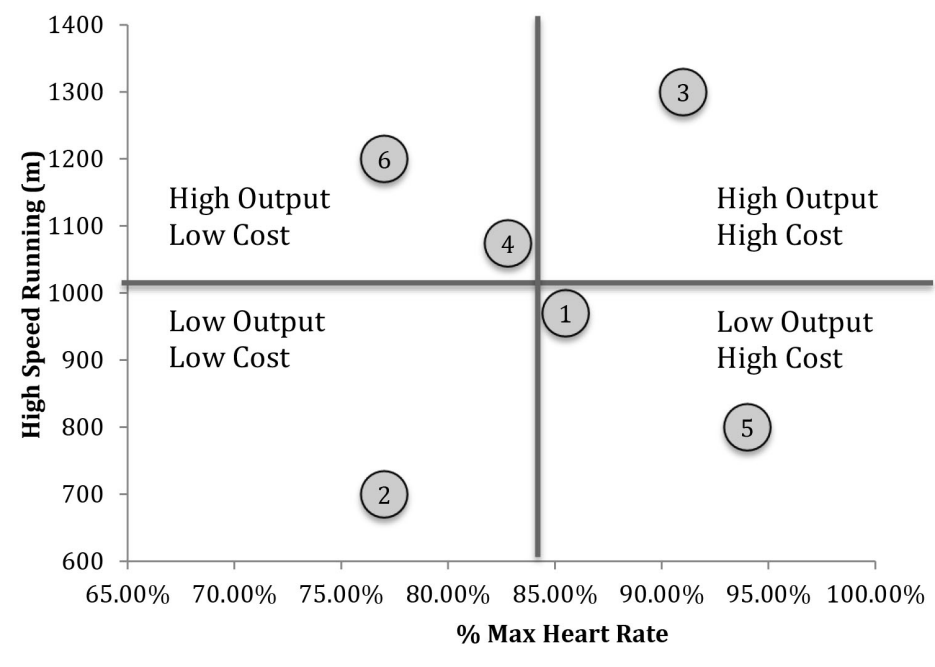

Figure 3 - Internal versus external load as represented by average heart rate and high-speed running. The cross-hair lines in the graph represent group averages for the session completed. Players 1, 2, 3, and 4 demonstrate appropriate work rate:cost ratios. Player 5 displays low work rate with a high cost and therefore warrants further investigation. Player 6 demonstrates high work rate with a low cost and therefore demonstrated superior fitness in this session.

recovery period. This method provides minimal disruption to the session. However SSMPs should ensure identical work is performed before the HRR assessment period. Second, a known quantity of work can be followed by a standard HRR assessment period of rest. Submaximal protocols have been designed for this purpose and offer a safe, quick, and reliable assessment tool..$^{50,51}$ Some debate exists as to the appropriate intensity of the work ${ }^{52}$ performed before HRR assessment and this can be difficult to establish in large groups of players with varying fitness levels. However, the practicality of these protocols as well as their demonstrated tracking ability across time, makes them a viable option for internal:external-load ratio monitoring.

\section{Conclusion}

SSMPs practitioners working within elite team sports environments are challenged with implementing evidenced-based load-monitoring practices that are appropriate to their specific environment. Factors to consider include coaching philosophy, player compliance and resources as well as the available evidence. The combination of these factors should influence monitoring choices rather than evidence alone.

\section{Practical Applications}

Evidence should guide SSMPs in their choice of monitoring strategies in elite team sports. However, often circumstances prevent implementation of strategies as they appear in the literature. In these cases SSMPs should validate their adjusted strategies. SSMPs are encouraged to publish their internal validation as they will drive future applications in this area. Universities should also be encouraged to partner with elite teams to drive academic rigor in their data-collection procedures. The combination of internal- with external-load monitoring perhaps provides the ideal scenario to assess player fitness, fatigue, and readiness to train or play.

\section{References}

1. Borresen J, Lambert MI. Quantifying training load: a comparison of subjective and objective methods. Int J Sports Physiol Perform. 2008;3(1):16-30. PubMed doi:10.1123/ijspp.3.1.16

2. Scott BR, Lockie RG, Knight TJ, Clark AC, De Jonge XAKJ. A comparison of methods to quantify the in-season training load of professional soccer players. Int J Sports Physiol Perform. 2013;8(2):195-202. PubMed doi:10.1123/ijspp.8.2.195

3. Meeusen R, Duclos M, Foster C, et al. Prevention, diagnosis and treatment of the overtraining syndrome: joint consensus statement of the European College of Sport Science (ECSS) and the American College of Sports Medicine (ACSM). Eur J Sport Sci. 2013;13(1):1-24. doi:10.1080/17461391.2012.730061

4. Wallace LK, Slattery KM, Coutts AJ. The ecological validity and application of the session-RPE method for quantifying training loads in swimming. J Strength Cond Res. 2009;23(1):33-38. PubMed doi:10.1519/JSC.0b013e3181874512

5. Coutts AJ, Duffield R. Validity and reliability of GPS devices for measuring movement demands of team sports. J Sci Med Sport. 2010;13(1)133-135. PubMed doi:10.1016/j.jsams.2008.09.015

6. Cummins C, Orr R, O'Connor H, West C. Global positioning systems (GPS) and microtechnology sensors in team sports: a systematic review. Sports Med. 2013;43(10):1025-1042. PubMed doi:10.1007/ s40279-013-0069-2

7. Mooney M, O'Brien B, Cormack S, Coutts A, Berry J, Young W. The relationship between physical capacity and match performance in elite Australian football: a mediation approach. J Sci Med Sport. 2011;14(5):447-452. PubMed doi:10.1016/j.jsams.2011.03.010

8. Gabbett TJ, Ullah S. Relationship between running loads and soft-tissue injury in elite team sport athletes. J Strength Cond Res. 2012;26(4):953-960. PubMed doi:10.1519/JSC.0b013e3182302023

9. Gaudino P, Iaia FM, Alberti G, Strudwick AJ, Atkinson G, Gregson W. Monitoring training in elite soccer players: systematic bias between running speed and metabolic power data. Int J Sports Med. 2013;34(11):963-968. PubMed doi:10.1055/s-0033-1337943

10. Kempton T, Sullivan C, Bilsborough JC, Cordy J, Coutts AJ. Match-to-match variation in physical activity and technical skill measures in professional Australian football. J Sci Med Sport. 2015;18(1):109-113. PubMed doi:10.1016/j.jsams.2013.12.006

11. Reid LC, Cowman JR, Green BS, Coughlan GF. Return to play in elite rugby union: application of global positioning system technology in return-to-running programs. J Sport Rehabil. 2013;22(2):122129. PubMed doi:10.1123/jsr.22.2.122

12. Blanch P, Gabbett TJ. Has the athlete trained enough to return to play safely?: the acute:chronic workload ratio permits clinicians to quantify a player's risk of subsequent injury. Br J Sports Med. 2016;50(8):471-475. PubMed doi:10.1136/bjsports-2015-095445

13. Hulin BT, Gabbett TJ, Lawson DW, Caputi P, Sampson JA. The acute:chronic workload ratio predicts injury: high chronic workload may decrease injury risk in elite rugby league players. Br J Sports Med. 2016;50(4):231-236. PubMed doi:10.1136/ bjsports-2015-094817

14. Gabbett TJ. The training-injury prevention paradox: should athletes be training smarter and harder? Br J Sports Med. 2016;50(5):273280. PubMed doi:10.1136/bjsports-2015-095788

15. Rogalski B, Dawson B, Heasman J, Gabbett TJ. Training and game loads and injury risk in elite Australian footballers. J Sci Med Sport. 2013;16(6):499-503. PubMed doi:10.1016/j.jsams.2012.12.004

16. Halson SL. Monitoring training load to understand fatigue in athletes. Sports Med. 2014;44(Suppl 2):S139-S147. PubMed doi:10.1007/ s40279-014-0253-z 
17. Lovell TW, Sirotic AC, Impellizzeri FM, Coutts AJ. Factors affecting perception of effort (session rating of perceived exertion) during rugby league training. Int J Sports Physiol Perform. 2013;8(1):62-69. PubMed doi:10.1123/ijspp.8.1.62

18. Impellizzeri FM, Rampinini E, Coutts AJ, Sassi A, Marcora SM. Use of RPE-based training load in soccer. Med Sci Sports Exerc. 2004;36(6):1042-1047. PubMed doi:10.1249/01. MSS.0000128199.23901.2F

19. Gabbett TJ, Jenkins DG. Relationship between training load and injury in professional rugby league players. J Sci Med Sport. 2011;14(3):204209. PubMed doi:10.1016/j.jsams.2010.12.002

20. Gabbett TJ. The development and application of an injury prediction model for noncontact, soft-tissue injuries in elite collision sport athletes. J Strength Cond Res. 2010;24(10):2593-2603. PubMed doi:10.1519/JSC.0b013e3181f19da4

21. Killen NM, Gabbett TJ, Jenkins DG. Training loads and incidence of injury during the preseason in professional rugby league players. J Strength Cond Res. 2010;24(8):2079-2084. PubMed doi:10.1519/ JSC.0b013e3181ddafff

22. Scott TJ, Black CR, Quinn J, Coutts AJ. Validity and reliability of the session-RPE method for quantifying training in Australian football: a comparison of the CR10 and CR100 scales. J Strength Cond Res. 2013;27(1):270-276. PubMed doi:10.1519/JSC.0b013e3182541d2e

23. Eston R. Use of ratings of perceived exertion in sports. Int $J$ Sports Physiol Perform. 2012;7(2):175-182. PubMed doi:10.1123/ ijspp.7.2.175

24. Gastin PB, Meyer D, Robinson D. Perceptions of wellness to monitor adaptive responses to training and competition in elite Australian football. J Strength Cond Res. 2013;27(9):2518-2526. PubMed doi:10.1519/JSC.0b013e31827fd600

25. Faude O, Kellmann M, Ammann T, Schnittker R, Meyer T. Seasonal changes in stress indicators in high level football. Int J Sports Med. 2011;32(4):259-265. PubMed doi:10.1055/s-0030-1269894

26. Silva ASR, Santhiago V, Papoti M, Gobatto CA. Psychological, biochemical and physiological responses of Brazilian soccer players during a training program. Sci Sports. 2008;23(2):66-72. doi:10.1016/j.scispo.2007.10.010

27. Montgomery PG, Hopkins WG. The effects of game and training loads on perceptual responses of muscle soreness in Australian football. Int J Sports Physiol Perform. 2013;8(3):312-318. PubMed doi:10.1123/ ijspp.8.3.312

28. Buchheit M, Racinais S, Bilsborough JC, et al. Monitoring fitness, fatigue and running performance during a pre-season training camp in elite football players. J Sci Med Sport. 2013;16(6):550-555. PubMed doi:10.1016/j.jsams.2012.12.003

29. Banfi G, Del Fabbro M, Mauri C, Corsi MM, Melegati G. Haematological parameters in elite rugby players during a competitive season. Clin Lab Haematol. 2006;28(3):183-188. PubMed doi:10.1111/j.1365-2257.2006.00771.x

30. Lazarim FL, Antunes-Neto JMF, da Silva FOC, et al. The upper values of plasma creatine kinase of professional soccer players during the Brazilian national championship. J Sci Med Sport. 2009;12(1):85-90. PubMed doi:10.1016/j.jsams.2007.10.004

31. Meyer T, Meister S. Routine blood parameters in elite soccer players. Int J Sports Med. 2011;32(11):875-881. PubMed doi:10.1055/ s-0031-1280776

32. Heisterberg MF, Fahrenkrug J, Krustrup P, Storskov A, Kjær M, Andersen JL. Extensive monitoring through multiple blood samples in professional soccer players. J Strength Cond Res. 2013;27(5):1260-1271. PubMed doi:10.1519/JSC.0b013e3182653d17

33. Filaire E, Lac G, Pequignot JM. Biological, hormonal, and psychological parameters in professional soccer players throughout a competitive season. Percept Mot Skills. 2003;97(3 Pt 2):1061-1072. PubMed doi:10.2466/pms.2003.97.3f.1061

34. Morton JP, Iqbal Z, Drust B, Burgess D, Close GL, Brukner PD. Seasonal variation in vitamin $\mathrm{D}$ status in professional soccer players of the English Premier League. Appl Physiol Nutr Metab. 2012;37(4):798-802. PubMed doi:10.1139/h2012-037

35. Crewther BT, Sanctuary CE, Kilduff LP, Carruthers JS, Gaviglio CM, Cook CJ. The workout responses of salivary-free testosterone and cortisol concentrations and their association with the subsequent competition outcomes in professional rugby league. J Strength Cond Res. 2013;27(2):471-476. PubMed doi:10.1519/JSC.0b013e3182577010

36. Hunkin SL, Fahrner B, Gastin PB. Creatine kinase and its relationship with match performance in elite Australian rules football. J Sci Med Sport. 2014;17(3):332-336. PubMed

37. Kraemer WJ, Looney DP, Martin GJ, et al. Changes in creatine kinase and cortisol in National Collegiate Athletic Association Division I American football players during a season. J Strength Cond Res. 2013;27(2):434-441. PubMed doi:10.1519/JSC.0b013e318281d1b0

38. Cormack SJ, Newton RU, McGuigan MR, Cormie P. Neuromuscular and endocrine responses of elite players during an Australian rules football season. Int J Sports Physiol Perform. 2008;3(4):439-453. PubMed doi:10.1123/ijspp.3.4.439

39. Twist C, Highton J. Monitoring fatigue and recovery in rugby league players. Int J Sports Physiol Perform. 2013;8(5):467-474. PubMed doi:10.1123/ijspp.8.5.467

40. Alexandre D, da Silva CD, Hill-Haas S, et al. Heart rate monitoring in soccer: interest and limits during competitive match play and training, practical application. J Strength Cond Res. 2012;26(10):2890-2906.

41. Plews DJ, Laursen P, Stanley J, Kilding A, Buchheit M. Training adaptation and heart rate variability in elite endurance athletes: opening the door to effective monitoring. Sports Med. 2013;43(9):773-781. PubMed doi:10.1007/s40279-013-0071-8

42. Buchheit M, Millet GP, Parisy A, Pourchez S, Laursen PB, Ahmaidi S. Supramaximal training and postexercise parasympathetic reactivation in adolescents. Med Sci Sports Exerc. 2008;40(2):362-371. PubMed doi:10.1249/mss.0b013e31815aa2ee

43. Dennis J, Dawson B, Heasman J, Rogalski B, Robey E. Sleep patterns and injury occurrence in elite Australian footballers. J Sci Med Sport. 2016;19(2):113-116. PubMed doi:10.1016/j.jsams.2015.02.003

44. Morgenthaler T, Alessi C, Friedman L, et al. Practice parameters for the use of ActiGraphy in the assessment of sleep and sleep disorders: an update for 2007. Sleep. 2007;30(4):519-529. PubMed

45. Kushida CA, Chang A, Gadkary C, Guilleminault C, Carrillo O, Dement WC. Comparison of actigraphic, polysomnographic, and subjective assessment of sleep parameters in sleep-disordered patients. Sleep Med. 2001;2(5):389-396. PubMed doi:10.1016/ S1389-9457(00)00098-8

46. Opar DA, Piatkowski T, Williams MD, Shield AJ. A novel device using the Nordic hamstring exercise to assess eccentric knee flexor strength: a reliability and retrospective injury study. J Orthop Sports Phys Ther. 2013;43(9):636-640. PubMed doi:10.2519/ jospt.2013.4837

47. Cormack SJ, Mooney MG, Morgan W, McGuigan MR. Influence of neuromuscular fatigue on accelerometer load in elite Australian football players. Int J Sports Physiol Perform. 2013;8(4):373-378. PubMed doi:10.1123/ijspp.8.4.373

48. McKeown I, Taylor-McKeown K, Woods C, Ball N. Athletic ability assessment: a movement assessment protocol for athletes. Int J Sports Phys Ther. 2014;9(7):862-873. PubMed

49. Bahr R. Why screening tests to predict injury do not work-and probably never will . . . : a critical review. Br J Sports Med. 2016;50(13):776-780. PubMed doi:10.1136/bjsports-2016-096256 
50. Buchheit M, Rabbani A. The 30-15 Intermittent Fitness Test versus the Yo-Yo Intermittent Recovery Test Level 1: relationship and sensitivity to training. Int J Sports Physiol Perform. 2014;9(3):522-524. PubMed doi:10.1123/ijspp.2012-0335

51. Veugelers K, Naughton G, Duncan C, Burgess D, Graham S. Validity and reliability of a submaximal intermittent running test in elite
Australian football players. J Strength Cond Res. 2016;30(12):33473353. doi:10.1519/JSC.0000000000001441

52. Daanen HA, Lamberts RP, Kallen VL, Jin A, Van Meeteren NL. A systematic review on heart-rate recovery to monitor changes in training status in athletes. Int J Sports Physiol Perform. 2012;7(3):251-260. PubMed doi:10.1123/ijspp.7.3.251 